\title{
A prática de Comblin: a Igreja do chão da realidade
}

\author{
The practice of Comblin: the Church on the ground of reality
}

Alzirinha Rocha de Souza*

\begin{abstract}
Resumo
É fato incontestável que a velocidade da história nos tem atropelado enquanto agilidade de Igreja. Não raro hoje, há um descompasso entre as demandas que o mundo nos faz e os processos de evangelização que com ele estabelecemos. Contudo, em diferentes épocas da Igreja, em especial da Igreja latino-americana, surgem novas iniciativas. É justamente o que queremos expor neste artigo: três ações concretas da prática de José Comblin, que entendia que, sem a compreensão da realidade e das necessidades imediatas dos pobres, não se poderia realizar um projeto eficaz de evangelização. A exposição de forma mais detalhada da experiência da enxada (voltada para a formação rural dos seminaristas), a experiência das CEBs e as Escolas de Formação Missionária (voltadas para a formação de missionários leigos e idealizadas por Comblin e sua equipe), são três exemplos de novos processos que, atendendo a públicos diferentes, buscam suprir a ausência de agentes evangelizados no vasto território do agreste nordestino.
\end{abstract}

Palavras Chaves: Cebs; Experiência da Enxada; Escolas de Formação Missionária; Leigos; Missão.

\begin{abstract}
It is undeniable fact that the speed of the story has hit us as Church agility concerns. Often today, there is a mismatch between the demands that the world makes us and evangelization processes that we have established. However, at different times of the Church, especially of the Latin American Church, there are new initiatives. It is precisely what we want to expose in this article: three concrete actions by Joseph Comblin, who noticed that without understanding the reality and the immediate needs of the poor, it would not be possible to perform an effective evangelization project. The exhibition in more detail on the Experience of the hoe, focused on rural formation of seminarians, the experience of the CEBS (Basic Ecclesial Communities) and missionary training Schools, dedicated to formation of lay missionaries, devised by Comblin and his team: these are three examples of new processes, serving different audiences, seeking to supply the absence of evangelized agents in the vast territory of the wild Northeast.
\end{abstract}

Keywords: CEBs (Basic Ecclesial Communities); Experience of the hoe; Schools dedicated to formation of lay missionaries; lay people; mission.

Artigo recebido em 29 de agosto de 2016 e aprovado em 28 de março de 2017.

${ }^{*}$ Doutora em Teologia - Université Catholique de Louvain (UCL), Bélgica. Mestre pela Universidade San Dámaso - Madrid, em 2009. É membro da Sociedade Internacional de Teologia Prática - SITP. Pesquisadora da PUCSP - Pós-Doutorado e Professora no ITESP/SP. País de Origem: Brasil. E-mail: alzirinharsouza@gmail.com.

Horizonte, Belo Horizonte, v. 15, n. 45, p. 239-255, jan./mar. 2017 - ISSN 2175-5841 


\section{Introdução}

A forma de ser Igreja de Francisco traz em seu seio dois imperativos maiores: a retomada da proximidade da realidade e das pessoas que nela estão inseridas e a recentralização dos pobres, ambos com vistas ao processo de evangelização que deve colocar a Igreja em confronto com os acidentes da história em que vivemos. Como expressado na Exortação Apostólica Evangelii Gaudium (EG), os cristãos são aqueles que devem "primeirear" na realidade, sobretudo na oferta alegre da Boa Nova de Jesus ao mundo. Dirá explicitamente Francisco: “ (...) prefiro uma Igreja acidentada, ferida e enlameada por ter saído pelas estradas a uma Igreja enferma pelo fechamento e pela comodidade de se agarrar às próprias seguranças" (EG, 49).

Ora, em épocas anteriores, houve na Igreja pessoas que "primeirearam" buscando essa proximidade, bem como a atualização e a viabilidade da formação e da evangelização. Não foram poucos os que, motivados pelos ventos pós-conciliares na América Latina, se colocaram à frente, procurando caminhos novos de ser Igreja.

Entre eles encontra-se José Comblin que, morando no Recife entre 1965 e 1972, buscava colocar em prática, juntamente com a comissão de formação e estudos do recém-fundado Instituto de Teologia do Recife (ITER), as propostas conciliares, seja para seminaristas, seja para leigos que eram admitidos pela primeira vez nos estudos teológicos.

Esse artigo quer apresentar a compreensão de serviço de sua teologia e as três expressões concretas que a corroboram. Na esteira do Concílio Vaticano II, Comblin consolida na prática o que defendia e compreendia como sua teologia: um serviço a ser prestado em especial aos pobres de forma que possa contribuir para seu desenvolvimento pessoal a partir do aprofundamento da compreensão de suas vidas com Deus. Para tanto, nosso autor forma três grandes núcleos de ação, inovadores em seu tempo, no Nordeste brasileiro: a formação rural de seminaristas 
que ficou amplamente conhecida como a Teologia da Enxada, o apoio e a dinamização das Comunidades Eclesiais de Base e, finalmente, as Escolas de Formação Missionárias para leigos e leigas que vieram a assumir grande parte da evangelização do agreste nordestino.

Não é necessário dizer que os três núcleos de ação sofreram sanções por parte de uma Igreja que se recusava a entrar na "modernidade pós-conciliar". Contudo, hoje em dia, poderíamos afirmar que Comblin cumpriria à risca o desejo de Francisco:

\begin{abstract}
Não quero uma Igreja preocupada com o ser o centro, e que acaba presa a um emaranhado de obsessões e procedimentos. [...] Mais do que o temor de falhar, espero que nos mova o medo de nos encerrarmos nas estruturas que nos dão uma falsa proteção, nas normas que nos transformam em juízes implacáveis, nos hábitos em que nos sentimos tranquilos enquanto lá fora há uma multidão faminta e Jesus repete-nos sem cessar: 'Dai-lhes vós mesmos de comer' (Mc 6,37). (EG, 49).
\end{abstract}

\title{
1 A coerência entre o sentido e a prática da teologia de Comblin
}

Algumas linhas de teologia tomam por base que o sentido do fazer teológico teórico é possível restringindo-se somente a articulação de conceitos. Outras não se compreendem sem a confirmação de sua teoria na prática. Outras, ainda, iniciam seu fazer teológico a partir da prática, das experiências concretas que pessoas fazem em seu cotidiano, considerando aí o espaço privilegiado de suas experiências com Deus. Notadamente, a última perspectiva é a de Comblin, reforçando a evidente contextualidade de sua teologia.

Essa contextualidade vem de dois conjuntos de elementos que se encontram: o pessoal e o profissional. Do primeiro, a inquietação pessoal em busca de uma Igreja viva diferentemente da Igreja europeia dos anos 1950 que, estando sob o papado de Pio XII, tendia à sacramentalidade; soma-se a isso a experiência missionária de seu irmão André Comblin que, pertencente à Congregação dos Padres Brancos, viveu em Ruanda até o evento do genocídio naquele país, quando, por razões de saúde, retornou à Bélgica. Do lado profissional, destacamos o 
interesse de Comblin em partilhar sua teologia de uma outra maneira que não a “tradicional”. Concluindo seu Doutorado em Bíblia na cidade de Leuven e tendo realizado algumas experiências no ensino das Sagradas Escrituras em Aalst, aos seminaristas que estavam em serviço militar, empenhando-se também no ensino acadêmico na América Latina trinta anos antes de sua morte, finalmente decidiu dedicar-se aos leigos e às formações "não acadêmicas".

Ora, considerando a análise de sua obra associada à sua caminhada pessoal e acadêmica, pode-se perceber que o deslocamento geográfico, cultural, histórico e o contexto, ao vir da Europa para a América Latina, foram determinantes no processo de mudança na construção teológica que realizou desde suas primeiras publicações.

Esse deslocamento, de forma global, permitiu que ele entrasse em contato com duas realidades bastante distintas que estão de certa maneira intervinculadas pelos "novos ventos" que sopravam na Igreja ao final dos anos 1950 e durante a década de 1960. Nesse sentido, afirmo que Comblin se situa em meio a dois cenários positivos: esteve com professores e formadores que, em sua maioria, participaram do processo de mudança da Igreja Conciliar e, por outro lado, instalou-se em uma realidade que pedia e esperava essas mudanças. A mudança de contexto geográfico, cultural e eclesial facilitou o distanciamento crítico e as novas posturas criativas, o que possibilitou o deslocamento teológico. Segundo Susin, tratou-se de uma releitura de mudança de lugar teológico que criou uma "ruptura epistemológica criativa”. (SUSIN, 2012, p. 126).

Contudo, a entrada de Comblin nesse novo meio teológico constitui-se num processo de aproximação, conhecimento e envolvimento com sua nova realidade. Em Campinas, descobriu não somente o que era um operário ${ }^{1}$, mas também como a Ação Católica se estabelecera no Brasil de maneira bastante diferente do que na Europa. (COMBLIN, 1961). Após sua primeira experiência em Campinas e na 
cidade de São Paulo por três anos, parte para o Chile, onde mescla o universo acadêmico (Universidade Católica de Santiago) com o pastoral. Começa a ganhar espaço em seu pensamento a relação direta entre teoria e prática e suas obras revelam a preocupação pela missão e evangelização nesse novo contexto.

Contudo, é no Nordeste brasileiro, após o ano de 1965 (quando se instala no Recife para assessorar D. Helder Câmara), que Comblin ritmiza seu processo de mudança teológica. A aproximação com os teólogos da TdLib, sua bagagem intelectual importada de Europa e a experiência pastoral em meio às classes populares foram determinantes nesse processo. A partir desse período, o processo acadêmico se converte cada vez mais em perspectiva prática. (COMBLIN, 2000, p.191).

De fato, o processo de mudança levou a encontrar o destinatário de sua teologia, o homem pobre latino-americano, e manteve-se em coerência "pensamento $\times$ prática". Ao longo de sua produção teológica, os temas que em início eram muito generalizados tornam-se cada vez mais especializados na abordagem antropológica. Comblin encontra o destinatário de sua teologia para quem ele deseja dedicar seu conhecimento, seu tempo.

O que queremos destacar, contudo, é que as mudanças pelas quais passou agregaram e o ajudaram positivamente a construir o direcionamento de sua teologia: como poucos, consegue colocar em consonância seu arcabouço intelectual e prático, solidificando em sua prática a compreensão teórica de que Teologia não pode ser outra coisa senão serviço. Nessa perspectiva, a compreensão e o sentido teológico de Comblin estão diretamente ligados à concepção mesma que ele tem do papel e da utilidade da teologia. Esta última não é, em absoluto, a que vem tentar ser linguagem de revelação de Deus. Tal maneira de pensar foi utilizada na tentativa de fechar Deus dentro da tecnicidade para converter os técnicos dessa linguagem nos únicos capazes de entendê-la, transformando-os em intermediários entre Deus e a humanidade, num exercício claro de poder que sempre ficou nas mãos de poucos. 
É em sentido diametralmente inverso que se encontra o pensamento de nosso autor. Para ele, a verdadeira teologia é a que se dá ao serviço da caridade vivida e ativa. Não uma teologia que pretende servir, mas que serve de verdade. Embora limitada pela interpretação de tempo no contexto em que é produzida, a veracidade da teologia consiste na insistência em pronunciar as palavras de que se necessita no momento exato em que precisam ser pronunciadas (COMBLIN, 1977, p.66). É necessário que toda teologia deixe de ser um "grande enunciado" da Palavra de Deus e se compreenda como "simples palavra de Deus", de forma que os prioritários de Deus, os pobres, possam entendê-la. O que legitima a teologia não são as belas palavras e os grandes escritos, mas o movimento de sair de sua centralidade complexa e distribuir-se entre os pobres. (COMBLIN, 1977, p.68).

Por conseguinte, a responsabilidade do teólogo é dar-lhe uma função social, não falar somente a si mesmo ou a um círculo privilegiado, mas traduzir a teologia, libertá-la de todas as complicações, das fórmulas pelas quais a fé se enreda, de tal forma que todos os cristãos possam, a partir de sua simplicidade e por ela, encontrar o novo de Deus na história. A teologia é verdadeira se serve a essa tarefa.

A teologia tem sentido a partir da referência da Palavra de Deus que se concretiza em uma forma de ação determinada da Igreja e do mundo. Falar de um tema teológico sem contato com a realidade humana não tem sentido. Os temas adquirem sentido no momento em que encontram uma nova vida, uma nova ação que passa essencialmente pela caridade. Os atos assumem um sentido para nós à medida que os temas são reatualizados na ação histórica. Tocar num tema teológico sem referência à prática não é mais que evocar uma estrutura que cai no vazio. (COMBLIN, 1977, p.72). Por isso dirá Comblin que a teologia se revela como discurso sobre as relações. Antes de tudo, a relação estabelecida entre Deus mesmo e a humanidade, que deve perpassar as relações interpessoais entre humanos. A primeira se dá na pessoa de Jesus, donde se entende que a teologia vem a ser, em sentido estrito, uma cristologia. Seu objeto próprio e único é Jesus, no qual Deus e o homem se encontram e estabelecem uma relação na verdade. Uma teologia que 
não acrescenta aos homens a revelação do Filho de Deus pela simplificação de linguagem é uma teologia ineficaz. (COMBLIN, 1977, p.79). A ruptura da compreensão da revelação de Deus na história na pessoa de Jesus afeta diretamente a construção do humano. Uma Igreja que não se reconhece frente às necessidades dos homens de seu tempo, onde a teologia não responde à atualidade, é uma Igreja fadada à autorreferencialidade, que tem por consequência última a incapacidade de realização de seu papel mais próprio, que é o anúncio do Evangelho. Afirmará Comblin: "É o que ocorre no mundo capitalista com aspiração pelo modelo tecnocrata (Cursilhos de Cristandade, Opus Dei, Clubes Serra etc.), é a tendência que represente melhor que qualquer outro livro o tão conhecido Caminho, que é quase a carta de cristianização do mundo tecnocrático". (COMBLIN, 1977, p.80).

Contudo, não se trata de criar um novo cristianismo, mas de relacionar os que demandam respostas, sem criar uma identificação que chegue a ser ideologização do cristianismo. Ou, ainda, sem criar oposição de forma a separar as pessoas que não se integram ao reduto estabelecido pela Igreja. Efetivamente, a responsabilidade e a importância da teologia estão em ajudar as pessoas e as ciências a darem voz a todos os homens na Igreja, na sociedade, mostrando respostas às suas questões concretas; não definindo suas ações, mas promovendoas a partir do trabalho de simplificação ou tradução da palavra de Deus, de forma concreta e em relação com suas realidades, o que permite o acesso do homem à compreensão de sua relação interpessoal com Deus na pessoa de Jesus Cristo. A prática de Comblin revela por inteiro sua compreensão de teologia.

\section{A prática de Comblin}

A prática pastoral de Comblin é reflexo de sua compreensão teológica, a exemplo dos projetos desenvolvidos no Nordeste brasileiro. Podemos dizer que, em sentido geral, sua prática pastoral compreende o sentido mesmo da teologia que defende: é a teoria posta ao serviço das pessoas, de tal forma que a aproxima e as 
ajuda a compreender sua relação com Deus. São práticas que buscam pôr as pessoas em contato com o Evangelho, dando-lhes um caminho para a conversão em suas vidas e o início de uma nova construção humana.

Em linha com a TdLib, podemos afirmar que sua prática: 1) parte igualmente da realidade, da preocupação por sua compreensão para que, num segundo momento, se possa emitir uma resposta teológica que contribua com o novo, com o que impulsiona ao futuro diferente; 2) tem como centralidade, parâmetro, prioridade e destinatários os pobres, os eleitos de Deus que estão continuamente mais abertos à esperança e à transformação do mundo; 3) põe a Igreja em movimento de aproximação com a realidade, refletindo uma Igreja Povo de Deus, comunitária e inclusiva, e 4) finalmente reflete as três características de Comblin no que toca à ação humana e cristã: esta deve ser profética, missionária e comunitária, de forma inter-relacionada e complementar.

Essas três características estão em cada uma de forma mais proeminente sem ser naturalmente excludentes. Dessa forma, em cada uma desses projetos marcantes criados e/ou acompanhados por Comblin estão refletidos os elementos que ele considera constituintes da ação cristã. Nesse sentido, apresentamos a Teologia da Enxada, marcada pela perspectiva profética dada pela formação realizada a partir da reflexão e denuncias das necessidades das comunidades onde viviam seus formandos; as Comunidades de Base, marcadas pela perspectiva da vivencia comunitária tendo por base a Palavra de Deus, e os Centros de Formação Missionária para leigos, marcados pela perspectiva missionária de formação de homens e mulheres dispostos a assumir a evangelização do meio rural no agreste brasileiro caracterizado pela escassez de sacerdotes. 


\subsection{A profecia que vem da Enxada}

O projeto de experiência de formação na área rural nasce em decorrência da solicitação dos seminaristas do ITER (Instituto Teológico do Recife), que à sua época lutavam por uma formação mais prática que teórica. De fato, desde que chegou ao Recife em 1965, Comblin trabalhou nos processos de formação internos do seminário e na academia. Capitaneados por Marcelo Carvalheira, Comblin e o pastoralista francês René Guerre, com larga experiência pastoral trazida do Seminário do Prado em Lyon e dos padres operários franceses, colaboraram com a estruturação do instituto que primava pela nova formação dos anos pós-conciliares para leigos e não-leigos. A visão da formação proposta em especial para os futuros sacerdotes se colocava em linha com o momento pós-conciliar e seria descrita por Marcelo Carvalheira: "Que sejam profetas do meio popular. Que vejam o que os outros não veem e promovam não somente palavras que consolam, mas também as que incomodam contra todas as desordens estabelecidas de toda sorte". (CARVALHEIRA, 1966, p.356). Efetivamente, Comblin era um estudioso dos modelos de formação sacerdotal herdados da romanização da segunda metade do século XIX, que representava nada mais que a transplantação do modelo europeu burguês à realidade brasileira.

É lutando contra esse modelo de formação que, em meio às outras ações, tais como a inserção de seminaristas nos bairros pobres do Recife e a autorização para o trabalho fora da pastoral, nasce o projeto que ficou conhecido como a Teologia da Enxada entre 1969 e 1971. Nesse modelo, a formação é centrada em torno das noções do humano e sua realidade, com atenção especial para a pastoral. Essa proposta buscava integrar e unificar a formação teológica com os diferentes aspectos da formação humana, cultural e afetiva dos participantes. Deslocava-se assim a estrutura tradicional seminarística para a prática, da experiência para a vivência, ao mesmo tempo que proporcionava um processo de evangelização e formação a partir da proximidade e compreensão da realidade em que estariam futuramente inseridos. (COMBLIN, 1974, p.14). 
A primeira experiência foi realizada nas comunidades de Tacaimbó em Pernambuco e Salgado na Paraíba, com dois grupos de seminaristas, a partir de um programa de vida construído pelo trabalho matinal junto com a comunidade especialmente rural. As tardes eram dedicadas aos estudos e as noites à pastoral. Seu objetivo segundo era a evangelização do meio rural concomitantemente à formação sacerdotal no mesmo contexto. As questões tratadas na formação vinham das demandas da comunidade, constituindo um programa dividido em quatro blocos chaves: 1) antropologia rural; 2) cristologia com o tema Jesus como revelador de Deus; 3) moral cristã a partir da compreensão de moralidade no cotidiano, e 4) eclesiologia e sacramentos.

Comblin repetirá essa experiência de formação na Diocese de Talca, no Chile, onde se instalou o Seminário de Alto de las Cruces no período de 1979-1988, e na Arquidiocese de João Pessoa (PB), na localidade do Arvazeado, junto com D. José Maria Pires, nos anos 1983-1984.

\section{A análise teológica}

Em sentido mais estrito, a experiência da Enxada situa Comblin em linha consigo mesmo e com sua compreensão do fazer teológico, que consiste no serviço a partir da centralidade do humano. Em sentido mais amplo, situa-o alinhado à realização das demandas pós-conciliares e à identificação com a TdLib.

Para Comblin, o mérito dessa experiência foi responder às diferenças de linguagem, de conceitos e de articulação de pensamento cultural e teológicos de uma classe média não qualificada para a evangelização de uma classe rural e pobre. (COMBLIN, 1974, p.14). Foi essa mesma proximidade que permitiu o surgimento da profecia, seja pela possibilidade de chamar os camponeses à ação e descobrir junto com eles como a revelação de Deus se faz igualmente pelas mediações políticas e públicas a partir do conhecimento profundo da realidade. 


\subsection{As CEBs: perspectiva comunitária}

As Comunidades Eclesiais de Base estiveram sempre presentes no pensamento de Comblin, não somente por sua nova perspectiva, mas sobretudo pela importância que o conceito de comunidade assume em seu pensamento. Em sua prática, ele lutava especialmente pela manutenção do que descrevia como essencial para ser mantido nessa nova organização que deveria em última instância constituir o conjunto das comunidades outras que se dizem eclesiais. Comblin destaca como características principais: 1) constituir a Igreja reunida, formada por grupos unidos, homogêneos e bem definidos que têm em vista ações bem determinadas; 2) por conseguinte, essas comunidades marcam e revelam uma definição clara de pessoas comprometidas e não comprometidas; 3) elas são efetivamente presença local da Igreja universal e sua unidade de ser e de ação representa a unidade da Igreja (sua unidade reflete a santidade, seus intercâmbios refletem a catolicidade e sua integração, a apostolicidade), e 4) nelas está a figura sempre presente dos animadores que assumem o desafio de sua unidade e a motivação dada pela prioridade às atividades comuns que finalmente são essenciais no eixo comunitário: trabalhos, reuniões, celebrações, estudos bíblicos e compartilhamento de problemas sociais. Elas não são somente uma imagem visível da vida comunitária essencialmente invisível, mas sua vida comunitária é caracterizada por uma relação horizontal de participação ativa. (COMBLIN, 1970, p.304).

Contudo, o mais importante para Comblin é o fato de que elas não representam, felizmente, um modelo universal de Igreja. Pelo contrário, representam um dos modelos dentro da realidade complexa, de facetas múltiplas, e uma das possibilidades para o que Comblin chamará de "outro projeto de Igreja", que é todo modelo que não represente o modelo romano único que paira sobre as realidades locais. A importância das Cebs se dá em função da descentralização que permite a seus participantes o amadurecimento eclesial a partir da construção de identidades que têm condições de atuar mais autonomamente e sem a estrutura paternilista oferecida pelo modelo romano. 


\subsection{Os Centros de Formação Missionária: a perspectiva da missão}

A experiência da missão, associada à formação de leigos e leigas, é especialmente a mais querida de Comblin. (ARQUIVO PESSOAL CARL LAGA, 2000). Se a experiência da Enxada era focada na mudança da formação sacerdotal, os CFM (Centros de Formação Missionária) são até hoje completamente dedicados à formação de leigos e leigas que residem e atendem às comunidades distantes dos grandes centros, no meio do agreste nordestino, aonde o clero, por diversas razões, não chega. Hoje, diríamos que muitas dessas mulheres aí formadas seriam sérias candidatas ao diaconato feminino.

A responsabilidade das CEBs está na revelação de novos ministérios laicos na pastoral e na comunidade, formados por responsáveis ou animadores reconhecidos como orientadores e aceitos como líderes em serviço intracomunitário.

Ora, em sentido oposto, nasceu na América Latina o ministério missionário leigo, no qual missionário é toda pessoa enviada por sua comunidade de origem para evangelizar os que não pertencem a ela, configurando uma Igreja itinerante rumo ao descobrimento do desconhecido que se põe em movimento no espaço e sai em busca de pessoas novas. Para Comblin, estas se constituem como uma expansão ou desenvolvimento do movimento das CEBs, ou melhor, uma nova etapa do mesmo movimento, operando nele mudanças substanciais. Trata-se de uma realidade nova à qual não se faz nenhuma alusão nos documentos eclesiais sobre as CEBs, passível de correção naquilo que ela poderia ter de rígido ou fechado em si mesmo. (COMBLIN, 1980, p.627). Missionários e CEBs se complementam em modos diferentes de viver.

Os missionários leigos são os que, impulsionados pelo Espírito de Jesus, assumem espontaneamente um modo de viver itinerante, evangelizando em povoados e lugares isolados e reunindo pessoas nas praças e nas ruas, com 
permissão da Igreja, iniciativa e disponibilidade pessoal. Trata-se de uma expressão de Igreja itinerante que circula pelos caminhos do mundo.

Entre as principais características que marcam a forma de viver para a qual os missionários são preparados nas CFM, temos as seguintes: 1) saem da comunidade de origem sem a intenção de se fixarem em outra comunidade, pois sua intenção maior é converterem-se em pessoas que tomarão a forma de estrangeiros em cada comunidade aonde chegarem; 2) não possuem autoridade sobre si mesmos pelo fato de serem missionários, a não ser a autoridade do Evangelho que levam consigo, anunciam e testemunham com seus exemplos de vida, e 3) realizam um intercâmbio de dons na comunidade com a qual mantém contato, oferecendo o seu dom que é a Palavra e recebendo a acolhida e a estrutura para continuarem a missão.

Ora, a prática missionária não é uma novidade para a Igreja, só que foi sendo anulada por diversas razões ao longo do tempo. Jesus foi o primeiro missionário itinerante, exemplo que foi seguido por seus discípulos. Os sinóticos relatam essa forma de evangelização baseada na disponibilidade pessoal total. Ao contrário das comunidades paulinas, que se direcionam a grupos constituídos (famílias, comunidades, pais e mães), os sinóticos sempre apontam para os que estão desintegrados da sociedade, isto é, os marginalizados. Posteriormente, a Didaqué (11-15) confirma também a prática missionária. Antes das comunidades de tipo paulino, os missionários itinerantes judaico-cristãos foram a primeira realização do seguimento de Jesus e o mais antigo modelo de cristianismo e seus discípulos. (COMBLIN, 1980, p.644).

É a partir da identificação da necessidade de missionários no processo de evangelização do Nordeste que Comblin dá início, em 1989, às Escolas de Formação Missionária. Inicialmente, o tema foi debatido junto aos bispos de Ruy Barbosa, Juazeiro, Senhor do Bonfim, Paulo Afonso, Barra, Vitória da Conquista, Guaratiba e Picos. Para avançar nesse processo, era preciso criar espaços de formação para leigos e uma formação estruturada que pudessem sustentar as 
inúmeras comunidades existentes sem suporte eclesial. Para tanto, fazia-se igualmente necessária uma formação adequada pedagógica e culturalmente em nível dos leigos, em sua maioria pessoas simples vindas da área rural. Por último, esse processo ganhou sua importância, como retomado na Conferência de Aparecida, a partir da constatação do avanço dos novos movimentos religiosos pentecostais sobre as classes mais pobres. Comblin afirmaria, em correspondência particular a seu amigo Padre Laga, que em muito contribuiu para a construção das escolas: "No Nordeste, os padres são tão escassos que são como máquinas de fazer sacramentos. Não lhes pode pedir mais que isso. As religiosas são dispersas em congregações distintas. Mas trabalham mais que os padres com o povo. Agora, o que está mesmo conquistando a América Latina são as igrejas do tipo pentecostal. Ali há um avanço fulminante. A Igreja perdeu o controle das massas e estas buscam a primeira Igreja que se apresenta a elas em suas culturas”. (ARQUIVO PESSOAL CARL LAGA, 1991).

Para o desenvolvimento das formações, que hoje totalizam 17, Comblin desenvolveu em conjunto com sua equipe uma série de livros de conteúdo teológico, em linguagem popular que dá ao futuro missionário a noção correta de como ele não deve ser: reduzido a grupos intraeclesiais (pastorais, liturgias e catequese). É essencial que a formação os conscientize e os “defenda do modelo que consiste em integrar o maior número possível de leigos em funções paroquiais ou de culto, deixando o mundo abandonado”. (ARQUIVO PESSOAL M. MUGGLER, 2007). A liberdade do missionário não consiste na recusa de dependências exteriores, mas na emancipação do espírito de forças de cumplicidade e dominação que o homem traz em si mesmo. (COMBLIN, 1973, p.61). Daí a necessidade de trabalhar de maneira mais profunda a personalidade do missionário para que ele seja capaz de dar testemunho, seja pela força da Palavra que destrói as estruturas, seja pela capacidade de lutar contra a dominação sem as armas dos dominadores, seja por ser um cristão que finalmente que está encarnado na história. É essa historicidade que faz a missão possível: a ação do missionário não ser repetição, 
mas invenção de um modelo que responde ao impacto da mensagem do Evangelho para o tempo em que se está sendo realizada.

\section{Conclusão}

Nesse percurso histórico, tivemos por objetivo apresentar as três ações inovadoras, seja por realização, seja por nova compreensão como no caso das CEBs, das quais Comblin participou ativamente, implementando-as sobretudo por perceber a realidade do contexto em que se encontrava e por acreditar na possibilidade de que novas ações eram possíveis nos processos constituintes da Igreja de Evangelização e Missão, muitas vezes nadando contra as correntes dos técnicos.

Visionário que era, Comblin via na proximidade e na compreensão da realidade a formação de leigos e leigas maduros na fé e, na consciência eclesial, a saída preventiva contra a secularização que invadia a Igreja europeia na qual viveu. Como ele mesmo dirá: "Qualquer que seja a deficiência dos resultados, invocaremos pelo menos o mérito de ter enfrentado o problema de uma pregação capaz de ser entendida pelo povo simples" (COMBLIN, 1974, p.14). Longe de afirmar a perfeição das ações aqui apresentadas, antes queremos dizer que estas foram válidas e possíveis de ser realizadas. Se para alguns olhares a Teologia da Enxada encerrava a perspectiva da formação em um só contexto (rural); as Escolas Missionárias pretendiam uma formação parcial frente a amplitude da Evangelização e as Cebs se comportaram em alguns momentos de forma independente da estrutura eclesial e posteriormente dependentes dessa, essas iniciativas não perdem de nenhuma forma o mérito de terem sido realizadas buscando suprir deficiências das já estabelecidas que, via de regra, não tomavam em consideração as demandas da realidade em que foram estabelecidas. Os desafios da Evangelização em áreas onde a estrutura eclesial é escassa pedem a urgência da realização de novas inciativas. 
Enfrentar é a palavra para as exigências de todos os tempos do processo evangelizador da Igreja? Creio que sim. Realmente, conforme afirma Francisco, não é possível pensar uma Igreja a-histórica, encerrada em si mesma, correndo o risco de perder o lugar que lhe é próprio.

\section{REFERÊNCIAS}

CARVALHEIRA, Marcelo. O tipo de padre que a Igreja espera após o Vaticano II. REB, Petrópolis, n.26, p.529-551, 1966.

COMBLIN, José. L'échec de l'action catholique? Éditions Universitaires: Paris, 1961.

COMBLIN, José. O conceito de Comunidade e a teologia. REB, Petrópolis, n.118, p.282308,1970 .

COMBLIN, José. Teologia da Missão. Petrópolis: Vozes, 1973.

COMBLIN, José. Teologia da Enxada. Petrópolis: Vozes, 1974.

COMBLIN, José. Teología. ¿Qué clase de servicio? In: Gibellini Rosino (org.). La nueva frontera de teología en América Latina. Salamanca, Sígueme, 1977, p. 282-308, 1977.

COMBLIN, José. O ministério missionário na América Latina. REB, Petrópolis, n.160, p.626-655, 1980.

COMBLIN, José. Questões a partir da prática das Cebs no Nordeste. REB, Petrópolis, n.198, p.335-381, 1990.

COMBLIN, José. Como vejo a teologia latino americana trinta anos depois. In: Luis Carlos SUSIN (org.). O Mar se abriu. Trinta anos de teologia na América Latina. São Paulo: Loyola, 2000. p. 78-95.

FRANCISCO, Papa. Exortação Apostólica Evangelii Gaudium. Disponível em: /w2.vatican.va/content/francesco/pt/apost_exhortations/documents/papafrancesco_esortazione-ap_20131124_evangelii-gaudium.html. Acesso em: 11 de outubro de 2016.

LAGA, Carl. Arquivo Pessoal Carl Laga (ACL). Carta de José Comblin, Serra Redonda, 20 set. 2000.

LAGA, Carl. Arquivo Pessoal Carl Laga (ACL). Carta de José Comblin, Serra Redonda, 27 nov. 1991. 
Muggler, Mônica, Barra. Arquivo Pessoal Mônica Muggler, Documento III, Escolas de Formação Missionária. Relatório do Seminário de avaliação. Serra Redonda, 10 a 12 de abril de 2007.

SUSIN, Luiz Carlos. José Comblin, um mestre da libertação. In: Eduardo HOONARERT (Org.). Novos desafios para o cristianismo. A contribuição de José Comblin. São Paulo: Paulus, 2012, p. 125-138. 